\title{
Inflammatory pseudotumor of the spleen concomitant with
} renal cell carcinoma: case report

\author{
Department of Pathology, Mie University School of Medicine, Mie, \\ Japan, and Department of Anatomical Pathology, Hospital de Clinicas, \\ Universidade Federal do Paraná, Curitiba, Brazil.
}

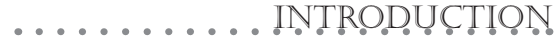

Inflammatory pseudotumors are rare lesions that can occur in virtually any organ. Their greatest significance is in relation to the inability to distinguish splenic inflammatory pseudotumors from malignant conditions, based solely on their clinical and radiological appearance. Splenic inflammatory pseudotumors are extremely rare, with only approximately 60 cases reported in the literature. Histologically, it is characterized by nonspecific and reparative changes resembling granulation tissue. ${ }^{1}$ Cases presenting with a concomitant neoplasm raise the suspicion of metastatic spread and are difficult to manage in the clinical setting, since accurate preoperative staging is, in most cases, impossible. We report on a case of splenic inflammatory pseudotumor presenting with concomitant renal cell carcinoma.

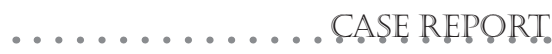

A 66-year-old man presented with complaints of a pelvic mass. Computerized tomography revealed a nodular tumor at the lower pole of the left kidney and an irregularly lobulated low-density splenic mass suggestive of splenic metastasis (Figure 1). No lymph node enlargement was observed. Angiographic examination of the left kidney showed a pattern highly suggestive of carcinoma. The patient underwent nephrectomy and, since no other site of systemic involvement was observed on computerized tomography scan, the spleen was also removed.

\section{Macroscopic findings}

The left kidney was deformed by an $8 \mathrm{x}$ $7 \times 6 \mathrm{~cm}$ soft white nodular mass at its lower pole. The tumor did not present renal capsule invasion, but renal vein involvement was present. A small metastasis was observed in the cortex, near the primary tumor. No hilar lymph nodes were positive for malignancy.

The spleen weighed $135 \mathrm{~g}$ and was altered by an irregularly lobulated white mass of hard consistency, measuring $10 \mathrm{~cm}$ in diameter. There were brown and yellow areas suggestive of old hemorrhage. No signs of thrombosis were observed in the hilar blood vessels.

\section{Histological findings}

Formalin-fixed paraffin-embedded tissue sections were obtained from both the renal and the splenic tumors, and were stained with hematoxylin-eosin. Histochemical analysis for reticulin fibers was also performed.

Microscopic evaluation of the renal tumor showed cells with clear cytoplasm and distinct cell membranes. The nuclei were slightly irregular and nucleoli were prominent, leading to a diagnosis of grade 2 clear cell renal carcinoma (Fuhrman grading system).

Histological examination of the splenic mass showed irregular dense collagen bundles with zones of fibroblastic proliferation in association with areas with lymphocytes, plasma cells and deposits of hemosiderin (Figure 2). Some areas showed concentric deposition of collagen in an "onion-skin" pattern. Reticulin staining showed islands of atrophic splenic tissue within the inflammatory lesion.
- Sérgio Ossamu loshii

- Danielle Giacometti Sakamoto

- Tiago Noguchi Machuca

- Ryuichi Yatani

Pyichi Yatani

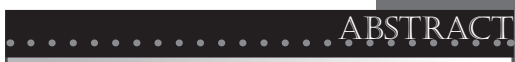

CONTEXT: Inflammatory pseudotumor is a rare benign lesion that can occur at a wide variety of primary sites. It is usually worrisome for the patient and the medical staff, since it cannot be clinically or radiologically distinguished from malignant entities.

CASE REPORT: We report on a case of splenic inflammatory pseudotumor presenting with concomitant renal cell carcinoma. Despite the alarming macroscopic appearance of pseudotumors, their microscopic features usually confirm the inflammatory nature of such lesions. Evidence regarding the etiology of pseudotumors is still lacking, but hypotheses have been created.

KEY WORDS: Spleen. Plasma cell granuloma. Renal cell carcinoma. Immunohistochemistry. Neoplasms. 


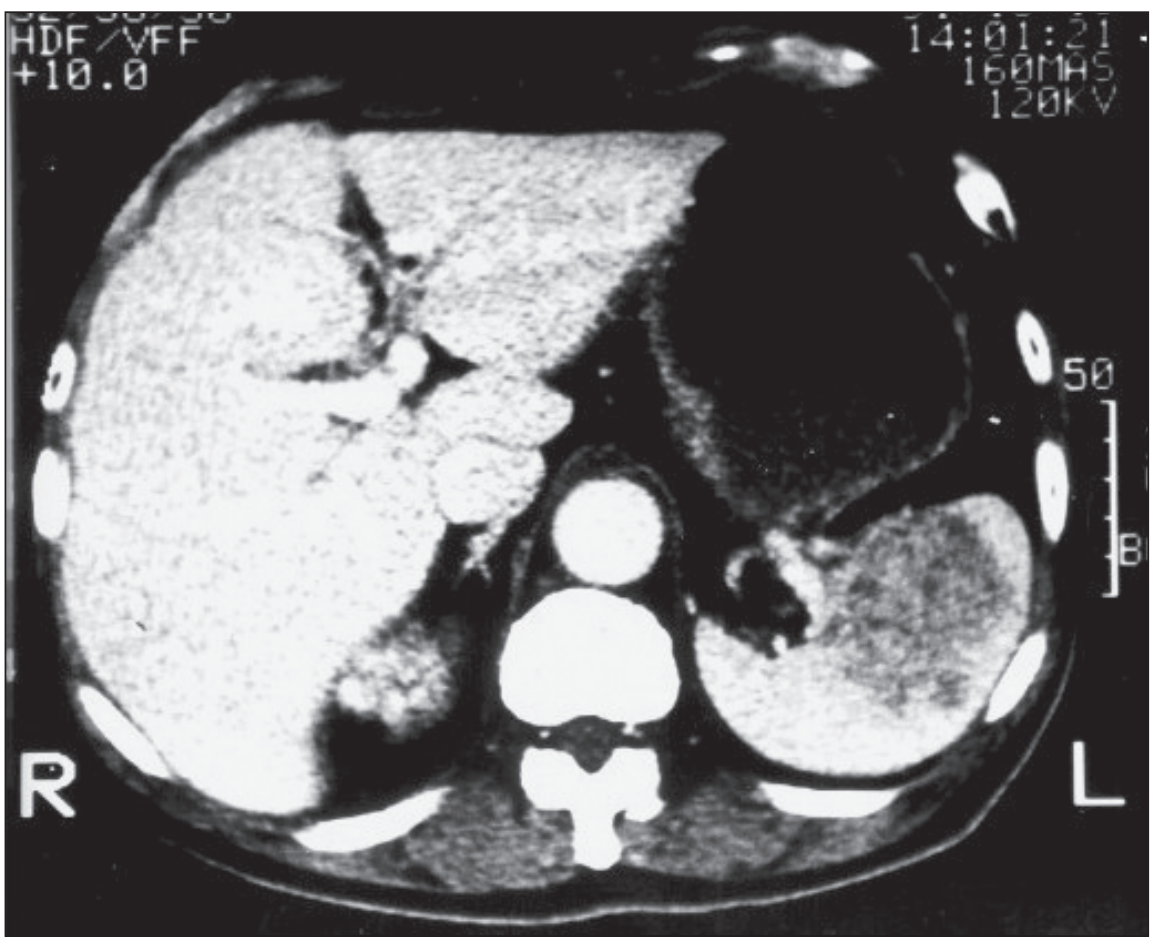

Figure 1. Computerized tomography displaying a lobulated splenic mass suggestive of a metastatic malignancy in a 66-year-old man.

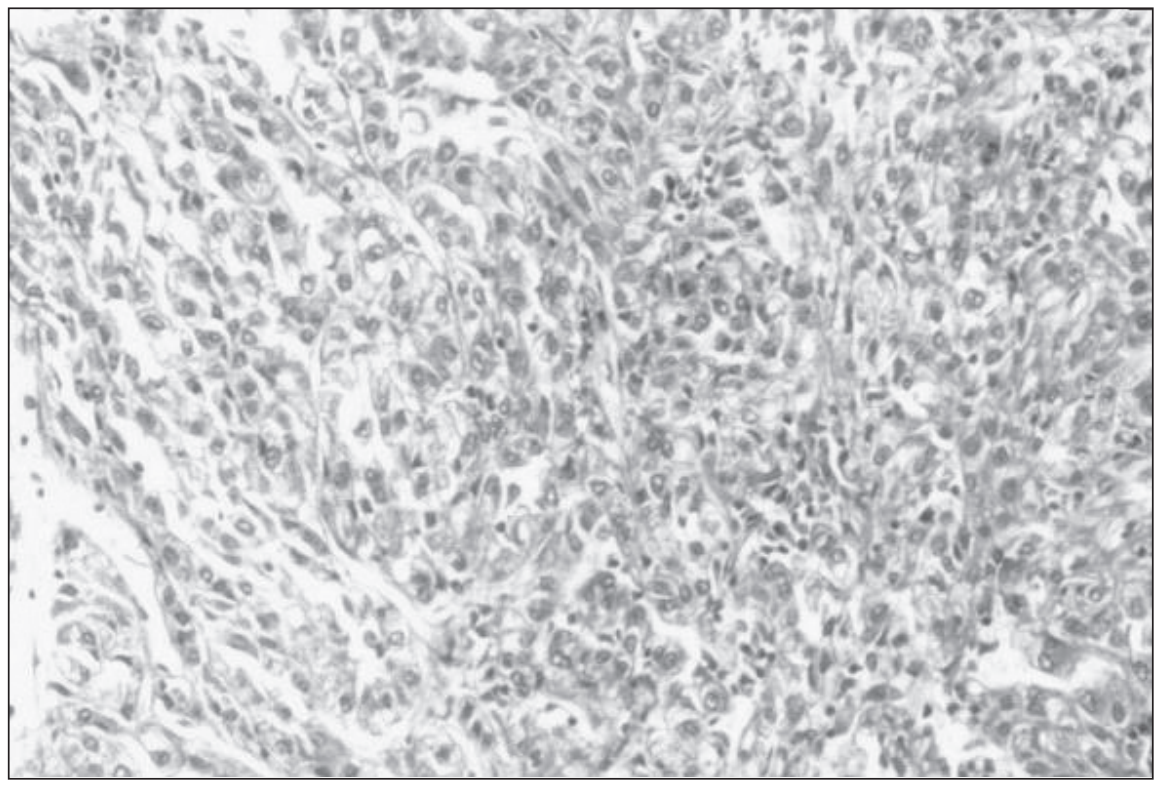

Figure 2. Photomicrography showing fibroblasts and lymphocytes of benign appearance, thus confirming the inflammatory nature of the tumor (hematoxylin-eosin, 200x).

\begin{tabular}{lccc}
\multicolumn{4}{c}{ Table $\begin{array}{c}\text { Immunohistochemical analysis of the renal and } \\
\text { splenic lesions of a }\end{array}$} \\
\hline Antibody & source/dilution & renal lesion & splenic lesion \\
\hline CKAE1/AE3 & Dako/1:400 & positive & negative \\
\hline Vimentin & Dako/1:1000 & positive, focal & positive \\
\hline Actin & Dako/1:3000 & negative & positive \\
\hline Desmin & Dako/1:200 & negative & positive \\
\hline CD34 & Dako/1:600 & negative & positive \\
\hline
\end{tabular}

The histological examination was suggestive of an inflammatory pseudotumor, but in order to rule out a possible metastatic focus from the renal lesion, immunohistochemical analysis was performed. The avidin-biotin-peroxidase method was employed and the results confirmed our suspicion (Table 1).

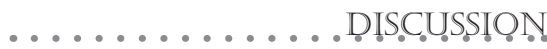

Splenic masses are most suggestive of lesions such as lymphoma, hematoma, abscess or infarct. Splenic inflammatory pseudotumors are rare, with only approximately sixty cases reported in the indexed world literature. The clinical presentation of splenic inflammatory pseudotumors is usually related to nonspecific signs and symptoms, or they may be detected incidentally during diagnostic workup for other diseases or during periodic clinical evaluation. The most frequent symptoms are abdominal pain, fatigue, weight loss, nausea, dyspepsia and night sweating. ${ }^{2}$ Among the signs, fever and leukocytosis are often present. ${ }^{2}$

Imaging studies of splenic inflammatory pseudotumors are as nonspecific as their clinical features. Plain radiography may show splenomegaly. Echography reveals that the tumor is usually hypoechoic and well demarcated. Computerized tomography with intravenous contrast medium may show a central stellate area corresponding to a fibrous plaque. This appearance has been reported as suggestive of splenic inflammatory pseudotumor. ${ }^{3}$ However, it is not possible to clearly detect splenic inflammatory pseudotumors solely on the basis of radiological data.

The treatment of splenic inflammatory pseudotumors consists of splenectomy. ${ }^{1}$ The published long-term follow-ups were uneventful and, to the best of our knowledge, no recurrence has been described in the literature. There have not been any cases of splenic inflammatory pseudotumors presenting or evolving with metastasis.

Because of their benign nature and favorable clinical course, the greatest dilemma regarding splenic inflammatory pseudotumors is in relation to whether splenic malignancies can be ruled out, thereby establishing pseudotumor as the correct diagnosis. Because of the nonspecific clinical presentation and unremarkable radiological appearance of pseudotumors, such distinction can only be established on the basis of histological analysis. Even in the absence of characteristic features such as nodal and 
bone marrow involvement, the most common preoperative diagnosis in splenic inflammatory pseudotumor cases is splenic lymphoma. ${ }^{1}$ In addition to lymphomas, the lesions frequently included in the differential diagnosis for splenic inflammatory pseudotumors are: lymphoreticular malignancies other than lymphomas (e.g. solitary plasmacytoma), hemangioma, tumoral proliferation of follicular dendritic reticulum cells, splenic hamartoma, reactive lymphoid hyperplasia and malignant fibrous histiocytoma.

In spite of the good demarcation presented by the tumor, it is not possible to rule out a malignant condition through macroscopic examination. Such a distinction can usually be achieved histologically. Upon microscopic examination, the tumor appears polymorphous, with spindle cells, a variable quantity of fibrocollagenous stroma and a granulomatous inflammatory component. There is predominance of lymphocytes (mostly T cells), plasma cells, histiocytes and, to a lesser extent, neutrophils and eosinophils. ${ }^{1,2}$ The features of the lymphocytes emphasize the benign nature of the tumor, with small, cytologically mature cells, absence of nuclear atypia and low mitotic activity. Centrally located areas of coagulative necrosis and areas of hemorrhage are often found. ${ }^{2}$

The etiology of splenic inflammatory pseudotumors remains unknown. Evidence favoring a possible infectious stimulus is still lacking. Except for sporadic reports, special stains and microbiological culturing have failed to detect an etiological agent. ${ }^{4}$ Their concomitant presentation with idiopathic thrombocytopenic purpura and the architectural similarities with Riedel's thyroiditis and idiopathic retroperitoneal fibrosis may point towards autoimmune pathogenesis. ${ }^{5}$ Nevertheless, further studies are necessary in order to support this hypothesis.

In summary, splenic inflammatory pseudotumors are rare benign lesions that should be considered when evaluating patients with splenic masses. The correct diagnosis is only made on the basis of microscopic findings and splenectomy is curative. The pathogenetic mechanisms involved in splenic inflammatory pseudotumors are not clear, but infectious and autoimmune hypotheses have been put forward.
1. Monteforte-Muñoz H, Ro JY, Manning JT, et al. Inflammatory pseudotumor of the spleen. Report of two cases with a review of the literature. Am J Clin Pathol. 1991;96(4):491-5.

2. Variami E, Terpos E, Vgenopoulou S, Kanellopoulou G, Meletis J. Inflammatory pseudotumor of the spleen: a case report and review of the literature. Ann Hematol.

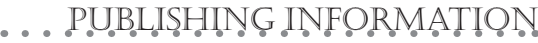

This report was partially presented at the Fourteenth Brazilian Congress of Pathology, Florianópolis, April 30 to May 4, 2003.

Sérgio Ossamu loshii. Pathologist, adjunct professor of Anatomical pathology, Hospital de Clínicas, Universidade Federal do Paraná, Curitiba, Brazil.

Danielle Giacometti Sakamoto. Resident in Anatomical Pathology, Hospital de Clínicas, Universidade Federal do Paraná, Curitiba, Brazil.

Tiago Noguchi Machuca. Medical student, Universidade Federal do Paraná, Curitiba, Brazil.

Ryuichi Yatani. Pathologist, professor of Pathology, Mie University School of Medicine, Mie, Japan.

Sources of funding: Tiago Noguchi Machuca is the recipient of a grant for scientific initiation program (PIBIC) from Universidade Federal do Paraná.

Conflict of interest: None

Date of first submission: October 31, 2003

Last received: March 5, 2004

Accepted: April 27, 2004

\section{Address for correspondence:}

Sérgio Ossamu loshii

Universidade Federal do Paraná, Serviço de Anato mia Patológica

R. General Carneiro, 18

Curitiba (PR) - Brasil - CEP 80069-900

Tel./Fax (+55 41) 264-1304

E-mail:soioshii@bsi.com.br
1999;78(12):560-3.

3. Franquet T, Montes M, Aizcorbe M, Barberena J, Ruiz De Azua Y, Cobo F. Inflammatory pseudotumor of the spleen: ultrasound and computed tomographic findings. Gastrointest Radiol. 1989;14(2):181-3.

4. Suster S, Moran CA, Blanco M. Mycobacterial spin- dle-cell pseudotumor of the spleen. Am J Clin Pathol. 1994;101(4):539-42.

5. Thomas RM, Jaffe ES, Zarate-Osorno A, Medeiros LJ. Inflammatory pseudotumor of the spleen. A clinicopathologic and immunophenotypic study of eight cases. Arch Pathol Lab Med. 1993;117(9):921-6. pseudotumor envolvendo o baço e apresentandose concomitantemente a um carcinoma renal de células claras. Apesar da semelhança macroscópica a tumores malignos, as características inflamatórias do pseudotumor são facilmente evidenciadas à microscopia. Apesar de hipóteses terem sido formuladas, os mecanismos patogenéticos relacionados ao pseudotumor ainda não estão bem estabelecidos.

PALAVRAS-CHAVE: Baço. Pseudotumor inflamatório. Carcinoma de células renais. Imunohistoquímica. Neoplasias. 